\title{
Menstrual Abnormalities and Their Association With Stress and Quality of Life Among Females Studying Health Sciences
}

Batool Alaskar ( $\sim$ Alaskar.batool@gmail.com )

King Saud bin Abdulaziz University for Health Sciences

Sara Alhunaif

King Saud bin Abdulaziz University for Health Sciences

Mise Alreem Shaheen

King Fahd Medical City

Hanan Alkadri

King Saud bin Abdulaziz University for Health Sciences

\section{Research Article}

Keywords: Menstrual abnormalities, perceived stress, Quality of life

Posted Date: August 31st, 2021

DOI: https://doi.org/10.21203/rs.3.rs-778062/v1

License: (c) (i) This work is licensed under a Creative Commons Attribution 4.0 International License. Read Full License 


\section{Title page:}

Menstrual Abnormalities and their Association with Stress and Quality of Life Among Females Studying Health Sciences

\section{Authors:}

Batool Alaskar, Medical Intern, King Saud bin Abdulaziz University for Health Sciences Sara Alhunaif, Medical Intern, King Saud bin Abdulaziz University for Health Sciences Mise Alreem Shaheen, Obstetrics and Gynecology resident, King Fahad Medical City Hanan Alkadri, Professor of Obstetrics and Gynecology, King Saud bin Abdulaziz University for Health Sciences

\section{Corresponding Author:}

Batool Alaskar, Medical Intern, King Saud bin Abdulaziz University for Health Sciences Email: Alaskar.batool@gmail.com

\section{Abstract}




\section{Background}

Menstrual abnormalities seem to occur more frequently in students studying medicine and health sciences. Menstrual abnormalities have the potential to impact women's health, their physical and emotional wellbeing as well as social and school functioning, there is a clear need for better understanding of these disease processes, their associations, and impact on quality of life. The present study aims to explore the association between menstrual abnormalities, psychological disturbances and eating disorders among female students studying health sciences subjects

\section{Methods}

This was a cross-sectional study, in which students from all health science colleges at King Saud bin Abdulaziz University for Health Sciences (KSAU-HS), Saudi Arabia, were asked to partake by answering questions pertaining to their demographic data, menstrual patterns, perceived stress, and quality of life using Perceived Stress Scale (PSS ) and the 20-Item Short Form Health Survey (SF-20) respectively. All statistical analyses were done using IBM SPSS Statistics software.

\section{Results}

Most respondents had a normal length cycle, duration and flow. Many of our respondents reported some type of premenstrual symptoms with mixed symptoms being the most prevalent $44 \%$. Those who had mixed premenstrual symptoms also had high levels of perceived stress $(\mathrm{p}<0.001)$. However, there was no correlation between menstrual cycle length and duration and levels of perceived stress. Regarding the SF-20 quality of life components who had premenstrual symptoms including pain, psychological symptoms, and mixed symptoms did poorly on the physical, social, and mental health aspects of quality of life.

\section{Discussion}

Our findings are in line with those identified by other authors who demonstrate a strong positive correlation with premenstrual symptoms and perceived stress and also an association between menstrual abnormalities and quality of life and activities of daily living. Due to the crosssectional nature of the study, causality cannot be determined and prospective studies are recommended in the future

\section{Conclusions:}

We found that those who had menorrhagia, premenstrual symptoms, or eating disorders reported high levels of stress. We have also demonstrated a link between premenstrual symptoms, menstrual abnormalities, PCOS , and worse quality of life. We hope that this unique study will shed some light on the struggles faced by health science female students and help policy makers enhance mental and reproductive/endocrinological health care access for them

\section{Keywords}

Menstrual abnormalities, perceived stress, Quality of life 


\section{List of abbreviations}

Presx:premenstrual symptoms.OCP:oral contraceptives. PCOS: polycystic ovarian syndrome

\section{Menstrual Abnormalities and their Association with Stress and Quality of Life Among Females Studying Health Sciences}

\section{Introduction}

Menstrual abnormalities are one of the most common gynecological complaints that have a significant impact on women's health status and quality of life. ${ }^{1}$ There are various types of menstrual abnormalities, including menorrhagia, polymenorrhea, abnormal vaginal bleeding, amenorrhea, oligomenorrhea, and dysfunctional vaginal bleeding. ${ }^{1,2}$ Menstrual disorders such as menorrhagia, abnormal uterine bleeding, and polymenorrhea contribute to almost $12 \%$ of gynecology referrals, and are usually associated with a very high chance of surgical interventions. ${ }^{1,3}$ A study done in Lebanon where 352 students completed a written questionnaire on menstrual abnormalities, showed that the most common menstrual disorders were irregular frequency of menstruation $(80.7 \%)$, premenstrual syndrome $(54.0 \%)$, abnormal duration of menstruation (43.8\%), followed by dysmenorrhoea , polymenorrhoea and oligomenorrhoea. ${ }^{4}$ In a similar study in Saudi Arabia, those complaining of irregular menstruation were (27\%), abnormal vaginal bleeding (9.3\%), amenorrhea (9.2\%), menorrhagia (3.4\%), dysmenorrhea $(89.7 \%)$, and premenstrual symptoms $(46.7 \%) .{ }^{1}$ These menstrual abnormalities not only carry an economic burden on the country, but are also one of the most common causes of absenteeism and poor academic performance among young females. Menstrual abnormalities seem to occur more frequently in students studying medicine and health sciences. ${ }^{1,4}$ One study identified menstrual problems in the young Saudi students to be as high as 91\%. ${ }^{1}$ This might be attributed to the continuous and chronic academic stress that health sciences students are under, resulting in negative health outcomes, including menstrual problems in females. ${ }^{5-7}$

Age, ethnicity, smoking, physical activity, and dietary habits are some factors that can impact menstrual variance among the population. In addition, Stress was found to be major contributor to menstrual abnormalities. An association has been documented between stress and various menstrual abnormalities including menorrhagia, oligomennorhea, dysmenorrhea, and premenstrual syndrome (PMS). ${ }^{8}$ In addition, a high proportion of women who reported suffering of menstrual abnormalities oligomenorrhoea or amenorrhoea had other complications such as polycystic ovary syndrome (PCOS), hirsutism or infertility. ${ }^{4,9}$ Other associated complications such as diet and eating disorders, exercise, and elevated body mass index (BMI) were also reported. For example, more than $60 \%$ of women with PCOS have elevated body mass index 
(BMI), and obesity which, in turn, leads to poor quality of life and psychological distress. ${ }^{10}$ Eating disorders, although rare, significantly affect quality of life, causing long-term health complications, and increase mortality rates by two-to six folds. ${ }^{10}$ They also burden individuals, their families, and society and pose a substantial economic burden on the healthcare systems. ${ }^{10,11}$ Women with PCOS and other menstrual abnormalities have higher risk of depression and anxiety, both known to be independently associated with eating disorders. Many of the physical characteristics of PCOS, such as hirsutism, obesity, irregular menstrual cycle, and infertility, contribute to lower self- esteem and body dissatisfaction, which in turn can lead to developing an eating disorders. ${ }^{11}$ As menstrual abnormalities have the potential to impact women's health, their physical and emotional wellbeing as well as social and school functioning, there is a clear need for better understanding of these disease processes, their associations, and impact on quality of life. ${ }^{12,13}$ The present study aims to explore the association between menstrual abnormalities, psychological disturbances and eating disorders among female students studying health sciences subjects. We hope that this unique study will shed some light on the struggles faced by health science female students and help policy makers enhance mental and reproductive/endocrinological health care access for them.

\section{Methods}

\section{Study design and participants}

This was a cross-sectional study, in which students from all health science colleges at King Saud bin Abdulaziz University for Health Sciences (KSAU-HS), in all of its three branches in Riyadh, Jeddah, and Alahsaa, Saudi Arabia, between March 2020 and June 2020 were invited to participate. In total, 821 female students participated in the study. Data on six students were removed due to incomplete answers, and data on the remaining 815 students were analyzed. Of the 815 female students included in the study, $65.4 \%$ were from Riyadh campus, $25.3 \%$ were from Jeddah, and 9.3\% were from Alahsaa. College of Medicine Students accounted for 314 (38.5\%) of the total study group, 220 (27\%) were from applied medical sciences, 109(13.4\%) were from nursing college, 57(7\%) were from dentistry college, and 48(5.9\%) were from college of pharmacology.

\section{Data collection}

The questionnaire included items relating to the participants' demographic details, and concerned their menstrual pattern (menarche age, cycle length in days, duration of flow in days, menstrual regularity), characteristics of blood loss, and history of dysmenorrhea, amenorrhea, and premenstrual symptoms). Normal menstruation was defined as a cycle occurring every 21-35 days, with a menstrual flow ranging from 2 to 6 days, and average blood loss is 20 to $80 \mathrm{ml}$ (equivalent to 5-7 pads/day). The questionnaire also included questions on eating disorders (i.e. anorexia nervosa, bulimia nervosa, and binge eating). Participant past history of polycystic ovarian syndrome, and use of oral contraceptive pills was collected. They also answered questions on quality of life using the 20-Item Short Form Health Survey (SF-20). The 20-Item Short Form Health Survey was developed for the Medical Outcomes Study (MOS), a multi-year study of patients with chronic conditions. For physical and role functioning, scores were reversed 
so that a high value reflected better functioning. After summing the scores for mental health scales, and reversing the scoring of some items, a high score indicated better health. Social functioning and more pain measures were scored so that high scores indicated better social functioning and more pain. Finally, for all parameters, scores were transformed linearly to 0-100 scales, with 0 and 100 being lowest and highest possible scores, respectively. ${ }^{14}$ Participants also answered questions on stress using Perceived Stress Scale (PSS). It measures the extent to which situations in one's life are perceived as stressful. The scale includes several direct queries about current levels of experienced stress. PSS scores are calculated by reversing responses (e.g., $0=4$, $1=3,2=2,3=1 \& 4=0$ ) to the four positively stated items (items $4,5,7, \& 8$ ) and then summing across all scale items. ${ }^{15}$

\section{Ethical consideration}

The present study was approved by the institutional review board at King Abdullah International Medical Research Center (KAIMRC). Participants consented to publishing their information; they were informed that participation is completely voluntary without positive or negative consequences. They were also informed that their identities will remain anonymous in the article and data would not be shared with any third party.

\section{Statistical analysis}

The distributions of the continuous variables were assessed for normality assumptions using Kolmogorov-Smirnov test, and these variables are expressed as mean( \pm standard deviation), and median [inter-quartile range (IQR)]. Frequencies and percentages were used to express categorical variables.

We first examined bivariate associations between perceived stress, and the demographic or clinical characteristics. Student's t-test was used for the data. For group comparisons with more than two groups, one-way analysis of variance (ANOVA) was used to compare the means of the study groups. Tukey test was performed to test the significance of pairwise differences. Spearman's correlation coefficients between perceived stress and Sf-20 components were computed to account for non-normally distributed or non-linearly related variables.

In our sample, among the SF-20 components, data from some subscales were normally distributed (Social functioning, Mental health, Health perception, and pain) and others were not normally distributed (physical functioning and role functioning). The measure of role functioning had minim distinct in the values where $38.3 \%$ of values were zero, and $61.7 \%$ of values were 50 or 100. For this reason, the measure was not included in further analyses. In addition, the common practice of analyzing the data using Mann-Whitney or Kruskal test is not appropriate with some of the outcome measures in our case as the data is discrete, skewed, and exhibit zeros a. A univariate analysis linear regression analysis followed by a multiple linear regression analysis were applied to explore all possible associations between clinical variables that could be significantly and independently be associated with measures of PSS and QoL, after adjusting for eating disorder and age as covariate. The adjustment is performed as both age and eating disorder have strong association with perceived stress and the QoL measures. Each measure of QoL and overall perceived stress were considered as dependent variables. All statistical tests were two tailed, and a p-value was considered significant at a level $<0.05$. Non-significant $p$-values are rounded to two decimal places. All statistical analyses were done using IBM SPSS Statistics software, version 23.0 (IBM Corp, Armonk, New York, USA). 


\section{Results}

\section{Sample characteristics}

Table 1 shows further breakdown of the sample characteristics. Mean age of students was 21.5 2.2 (range 18-31). Most of the students (45.4\%) reported their cycles to be between 21-27 followed by $39.1 \%$ of them reporting the length of their cycles to be between 28-34 days. The majority $82.2 \%$ had between 5-7 days of flow. For blood loss, $67.7 \%$ answered needing to change less than twice per day, 29.2\% had to change between 5-7 times per day, and only $3.1 \%$ had to change more than 7 times per day. $44 \%$ of the students reported having mixed premenstrual symptoms, $22.8 \%$ reported having lower abdominal pain predominantly, $13.7 \%$ had predominant psychological symptoms, breast tenderness accounted for $7.1 \%$, generalized body pain for $5.9 \%$, whereas acne, bloating, and other accounted for $4.3 \%$. Of our total study group, $88.1 \%$ didn't use oral contraceptive pills, and $87.1 \%$ weren't diagnosed with polycystic ovarian syndrome before. Eating disorders accounted for $5.9 \%$ of our study population, in which anorexia accounted for 3.3 of it, binge eating $2 \%$, and Bulimia $0.6 \%$.

$\underline{\text { Table 1. Demographic and clinical characteristics of the participants }(n=815)}$

\begin{tabular}{llc}
\hline & & Total subjects \\
\hline Age, years, mean \pm SD & & $21.5 \pm 2.2$ \\
Marital status & Single & $782(96)$ \\
Cycle length, days & Married & $33(4)$ \\
& $<21$ & $79(9.7)$ \\
& $21-27$ & $370(45.4)$ \\
Duration & $28-34$ & $319(39.1)$ \\
& $>35$ & $47(5.8)$ \\
Blood loss, pads/day & $<2$ & $37(4.5)$ \\
& $5-7$ & $670(82.2)$ \\
Pre sx & $>7$ & $108(13.3)$ \\
& (scarce) $<5$ & $552(67.7)$ \\
& (average)5-7 & $238(29.2)$ \\
& (Abundant) $>7$ & $25(3.1)$ \\
& Pain & $309(37.9)$ \\
ECOS & Generalized body pain & $48(5.9)$ \\
& Lower abdominal pain & $186(22.8)$ \\
& Headache & $17(2.1)$ \\
& Breast tenderness & $58(7.1)$ \\
& Psychological (Mood swings, anger, irritability) & $112(13.7)$ \\
& Mixed symptoms & $359(44)$ \\
& Acne, bloating, other & $35(4.3)$ \\
& Yes & $97(11.9)$ \\
& No & $718(88.1)$ \\
& Yes & $105(12.9)$ \\
& No & $710(87.1)$ \\
& Yes & $48(5.9)$ \\
& Anorexia & $27(3.3)$ \\
\hline
\end{tabular}


Abbreviations: . Presx:premenstrual symptoms.OCP:oral contraceptives. PCOS: polycystic ovarian syndrome All reported values are $\mathrm{n}(\%)$ of respondents except for age.

\section{Descriptive data for perceived stress and SF-20 and correlation coefficients}

Table 2 and 3 show an overview of the descriptive statistics for the perceived stress and the six SF-20 dimensions for the entire research sample. In our study group, the perceived stress score was low to moderate $(22.4 \pm 6.96)$ reaching up to $29.4 \%$ as high perceived stress. Table 3 gives the correlations between the scale scores and between the later and perceived stress score. Comparison of the correlations between the scale scores shows that the pattern of the correlations is low correlation, except for the perceived stress that was correlated most strongly and negatively with the mental health component $(\mathrm{r}=-0.61)$.

Table 2. Descriptive statistics for perceived stress among undergraduate health professional students $(\mathrm{n}=815)$.

\begin{tabular}{lcccc}
\hline \multicolumn{4}{c}{ Stress } & \\
\hline & N & \% & & \\
\hline Low and moderate & 575 & 70.6 & & \\
High & 240 & 29.4 & & \\
& Mean & Sd & Minimum & Maximum \\
Perceived stress score & 22.4 & 6.96 & 0 & 40 \\
\hline
\end{tabular}

Table 3. Descriptive statistics for SF-20 scale components ( $\mathrm{n}=815)$.

\begin{tabular}{|lc|}
\hline SF-20 measures & Median (IQR) \\
\hline Physical functioning (PF), & $66.7(16.7-100)$ \\
Social functioning (SF), & $80(40-100)$ \\
Mental health (MH), & $48(36-64)$ \\
Health perception (HP), & $60(45-75)$ \\
Pain (P) & $60(40-80)$ \\
\hline \multicolumn{2}{|}{ Higher values on each measure indicate better health expect for pain. } \\
Data are median (interquartile range) for SF-20 measures. \\
\hline
\end{tabular}

Table 4. Correlation of perceived stress and SF-20 components scores

\begin{tabular}{|l|l|l|l|l|l|l|}
\hline Instrument/subscale & $\begin{array}{l}\text { Perceived } \\
\text { stress }\end{array}$ & PF & SF & MH & HP & Pain \\
\hline Perceived stress & 1.0 & -0.12 & -0.20 & -0.61 & -0.44 & 0.18 \\
\hline PF & & 1.0 & 0.32 & 0.16 & 0.29 & -0.21 \\
\hline SF & & & 1.0 & 0.28 & 0.25 & -0.34 \\
\hline
\end{tabular}




\begin{tabular}{|l|l|l|l|l|l|l|}
\hline MH & & & & 1.0 & 0.34 & -0.20 \\
\hline HP & & & & & 1.0 & -0.10 \\
\hline Pain & & & & & \\
\hline Spearman rank correlation coefficient. For all correlations p-value <0.001. \\
\hline
\end{tabular}

\section{Results on perceived stress}

As shown in Table 5, students experiencing mixed symptoms scored a significantly higher perceived stress than those experiencing pain $(23.4 \pm 6.71$ vs $21.3 \pm 6.74, p=0.001)$ or acne, bloating or other symptoms $(23.4 \pm 6.71$ vs $19.7 \pm 8.22, \mathrm{p}=0.014)$. No statistically significant differences were observed in the other premenstrual symptoms. Females with blood loose more than 7 reported higher perceived stress compared with those with less blood loos, however, the difference in their perceived stress did not vary significantly, although it was close to significance $(\mathrm{p}=0.050)$. Age is significantly and negatively correlated with perceived stress ( $\mathrm{p}$ value $=0.002$ ). No significant associations were observed between the perceived stress and marital status, cycle length, duration, OCP, and PCOS.

Table 5. Association between perceived stress and demographics or clinical characteristics $(\mathrm{N}=815)$

\begin{tabular}{|lccc|}
\hline Variable & $\begin{array}{c}\text { Perceived stress } \\
(\text { mean } \pm \text { SD })\end{array}$ & $\begin{array}{c}\text { Statistical test } \\
(\mathrm{df})\end{array}$ & P-value \\
\hline Age, years & & $\mathrm{r}=-0.21^{\mathrm{a}}$ & 0.002 \\
Cycle length, days & & & \\
$<21$ & $22.1 \pm 6.46$ & $\mathrm{~F}=2.13(3,811)$ & 0.095 \\
$21-27$ & $22.9 \pm 7.09$ & & \\
$28-35$ & $21.7 \pm 6.99$ & & \\
$>35$ & $23.3 \pm 6.13$ & & 0.086 \\
Duration & & & \\
$<2$ & $24.6 \pm 7.36$ & $\mathrm{~F}=2.46(2,812)$ & \\
$5-7$ & $22.2 \pm 6.87$ & & \\
$>7$ & $22.9 \pm 7.28$ & & \\
Blood loss & $22.2 \pm 6.93$ & $\mathrm{~F}=2.16(2,812)$ & \\
$<5$ & $22.5 \pm 6.97$ & & \\
$5-7$ & $24.9 \pm 6.85$ & & \\
$>7$ & & & \\
PreSx & $21.3 \pm 6.74$ & $\mathrm{~F}=4.68(3,811)$ & \\
Pain & $23.1 \pm 7.33$ & & 0.001 \\
Psychological & $23.4 \pm 6.71$ & & \\
Mixed & $19.7 \pm 8.22$ & & 0.843 \\
Acne, bloating, other & $23.3 \pm 5.70$ & $\mathrm{t}=1.67(813)$ & \\
Ocp & $22.3 \pm 7.10$ & & \\
Yes & $22.3 \pm 6.69$ & $\mathrm{t}=-0.198(813)$ & \\
No & $22.4 \pm 7.0$ & & \\
PCOS & & & \\
Yes & & & \\
No & & & \\
\hline
\end{tabular}


Abbreviations: df, degrees of freedom

Comparisons of perceived stress score between duration, blood loss, presx were based on one-way analysis of variance and comparisons between age, ocp, pcos and eating disorder groups were based on t-tests.

${ }^{\mathrm{a}} \mathrm{r}=$ Pearson correlation

\section{Results on health-related quality of life}

For cycle length, those with cycle length less than 21 days had significantly lower social functioning compared to those with cycle length more than 35 days $(B=-14.2, p=0.006)$. Females with cycle length between 21-27 and 28-35 days had significantly higher health perception compared to those with cycle length longer than 35 days $(\mathrm{B}=6.97, \mathrm{p}=0.027$ and $\mathrm{B}=10.1, \mathrm{p}=0.002$, respectively). Duration levels did not affect any of the outcome measures differently. There was a significant correlation between those who had to change $<5$ times and between 5-7 times and physical and $(\mathrm{B}=21.3, \mathrm{P}=0.005, \mathrm{~B}=16.41, \mathrm{P}=0.036$ respectively), social functioning $(\mathrm{B}=29.3, \mathrm{P}=<0.001, \mathrm{~B}=7.05 \mathrm{P}=0.001)$. Those who had to change $<5$ times also had a significant negative correlation with pain compared to those who had to change $>7$ times $(\mathrm{B}=-14.3, \mathrm{P}=0.002)$

Those who reported having pain, psychological, or mixed symptoms had negative physical ( $\mathrm{B}=-16.07, \mathrm{P}=0.015, \mathrm{~B}=-10.8, \mathrm{P}=0.13, \mathrm{~B}=-20.73, \mathrm{P}=0.002$ ) Those who also reported more pain or mixed symptoms had negative social functioning $(\mathrm{B}=-12.9, \mathrm{P}=0.032, \mathrm{~B}=-18.8, \mathrm{P}=0.002$ respectively ). Student who had psychological or mixed symptoms had negative correlation with mental health $(\mathrm{B}=-11.6, \mathrm{p}=0.003, \mathrm{~B}=-10.9, \mathrm{P}=0.002)$

Participants reporting pain or mixed experienced more pain $(\mathrm{B}=12.6, \mathrm{P}=0.002, \mathrm{~B}=13.5, \mathrm{P}=0.001)$ Those using OCP had negative correlation with physical $(\mathrm{B}=-23.1, \mathrm{P}=<0.001)$ and social functioning $(\mathrm{B}=-20.9 \mathrm{P}=0.001)$, and health perception $(\mathrm{B}=-8.68, \mathrm{P}=<0.00)$ compared to those who are not on OCP.

Participants diagnosed with PCOS had negative physical functioning $(\mathrm{B}=-8.87, \mathrm{P}=0.023)$ and health perception $(\mathrm{B}=-4.38, \mathrm{P}=0.041)$ but reported less pain $(\mathrm{B}=-8.46, \mathrm{P}=-8.46)$ compared to those not diagnosed with PCOS.

Other variables that were significantly associated with the outcome measures were age and eating disorder. Age was positively and significantly correlated with physical function $(\mathrm{B}=2.84$, $\mathrm{p}<0.001)$, social functioning $(\mathrm{B}=1.65, \mathrm{p}=0.001)$, mental health $(\mathrm{B}=1.53, \mathrm{p}, 0.001)$, health perception $(1.62$, $\mathrm{p}$-value $<0.001)$, but negatively correlated with pain $(\mathrm{r}=-0.81, \mathrm{p}$-value $=0.007)$. Eating disorder was significantly associated with all outcome measures expect pain. Those with eating disorder had significantly lower physical functioning $(\mathrm{B}=-17.5, \mathrm{P}=0.002)$, social functioning $(\mathrm{B}=-13.5, \mathrm{P} 0.007)$, mental health $(\mathrm{B}=-13.1, \mathrm{P}=<0.001)$ and health perception $(\mathrm{B}=-$ $20.1, \mathrm{P}=0.001)$ compared to those with no eating disorder. 
Table 6 Univariate regression analysis .

\begin{tabular}{|c|c|c|c|c|c|c|c|c|c|c|c|c|c|c|c|}
\hline & \multicolumn{3}{|c|}{$\mathrm{PF}$} & \multicolumn{3}{|c|}{ SF } & \multicolumn{3}{|c|}{$\mathrm{MH}$} & \multicolumn{3}{|c|}{ HP } & \multicolumn{3}{|c|}{ Pain } \\
\hline & B & SE & $\mathrm{p}$ & B & SE & $\mathrm{p}$ & B & SE & $\mathrm{p}$ & B & SE & $\mathrm{p}$ & B & SE & $\mathrm{p}$ \\
\hline Age, years & 2.84 & 0.59 & $<0.001$ & 1.65 & 0.54 & 0.002 & 1.53 & 0.33 & $<0.001$ & 1.62 & 0.32 & $<0.001$ & -0.81 & 0.36 & 0.027 \\
\hline \multicolumn{16}{|l|}{\begin{tabular}{|l|} 
Cycle length \\
\end{tabular}} \\
\hline$<21$ & \begin{tabular}{|l|}
-11.2 \\
\end{tabular} & 6.83 & 0.10 & \begin{tabular}{|l|}
-17.2 \\
\end{tabular} & 6.2 & 0.006 & 0.06 & 3.8 & 0.98 & 0.17 & 3.74 & 0.96 & -2.17 & 4.19 & 0.61 \\
\hline $21-27$ & 1.27 & 5.74 & 0.82 & \begin{tabular}{|l|}
-10.1 \\
\end{tabular} & \begin{tabular}{|l|}
5.21 \\
\end{tabular} & 0.06 & \begin{tabular}{|l|}
-3.26 \\
\end{tabular} & 2.11 & 0.31 & 6.97 & 3.14 & 0.027 & -0.001 & 3.52 & 0.99 \\
\hline $28-35$ & 6.78 & \begin{tabular}{|l|}
5.79 \\
\end{tabular} & 0.24 & -3.26 & 5.26 & 0.53 & 0.49 & 3.2 & 0.88 & 10.1 & 3.17 & 0.002 & -1.61 & 3.55 & 0.65 \\
\hline \multicolumn{16}{|l|}{$>35^{\mathrm{a}}$} \\
\hline \multicolumn{16}{|l|}{ Duration } \\
\hline$<2$ & -8.61 & 7.11 & 0.23 & \begin{tabular}{|l|}
-7.52 \\
\end{tabular} & 6.46 & 0.24 & \begin{tabular}{|l|}
-6.40 \\
\end{tabular} & 3.93 & 0.10 & -7.77 & 3.88 & 0.05 & -7.55 & 4.31 & 0.08 \\
\hline $5-7$ & 2.59 & 3.87 & 0.50 & \begin{tabular}{|l|}
-0.09 \\
\end{tabular} & 3.51 & 0.98 & 2.87 & 2.14 & 0.18 & 3.69 & 2.11 & 0.08 & -4.07 & 2.35 & 0.08 \\
\hline \multicolumn{16}{|l|}{$>7$} \\
\hline \multicolumn{16}{|l|}{ Blood loos } \\
\hline$<5$ & 21.3 & 7.61 & 0.005 & \begin{tabular}{|l|}
29.3 \\
\end{tabular} & 6.85 & $<0.001$ & 5.46 & 4.23 & 0.19 & \begin{tabular}{|l|}
-0.77 \\
\end{tabular} & 4.19 & 0.86 & -14.3 & 4.59 & 0.002 \\
\hline $5-7$ & \begin{tabular}{|l|}
16.41 \\
\end{tabular} & 7.82 & \begin{tabular}{|l|}
0.036 \\
\end{tabular} & \begin{tabular}{|l|}
23.7 \\
\end{tabular} & \begin{tabular}{|l|}
7.05 \\
\end{tabular} & 0.001 & 4.89 & 4.35 & 0.26 & \begin{tabular}{|l|}
-0.72 \\
\end{tabular} & 4.32 & 0.87 & -8.67 & 4.73 & 0.07 \\
\hline \multicolumn{16}{|l|}{$>7$} \\
\hline \multicolumn{16}{|l|}{ presx } \\
\hline pain & -16.07 & 6.62 & 0.015 & -12.9 & 6 & 0.032 & -3.94 & 3.63 & 0.28 & 0.16 & 3.96 & 0.96 & 12.6 & 3.99 & 0.002 \\
\hline psychological & \begin{tabular}{|l|}
-10.8 \\
\end{tabular} & 7.19 & 0.13 & $\mid-9.39$ & 6.52 & 0.15 & \begin{tabular}{|l|}
-11.6 \\
\end{tabular} & 3.94 & 0.003 & -2.08 & 3.96 & 0.60 & 3.29 & 4.33 & 0.45 \\
\hline mixed & -20.73 & 6.57 & 0.002 & $\mid-18.8$ & 5.96 & 0.002 & \begin{tabular}{|l|}
-10.9 \\
\end{tabular} & 3.61 & 0.002 & -3.16 & 3.63 & 0.38 & 13.5 & 3.96 & 0.001 \\
\hline \multicolumn{16}{|c|}{ acne, bloating, other } \\
\hline \multicolumn{16}{|l|}{ OCP } \\
\hline yes & -23.1 & 3.96 & $<0.001$ & \begin{tabular}{|l|}
-20.9 \\
\end{tabular} & 3.59 & , 0.001 & -3.93 & 2.24 & 0.07 & -8.68 & 2.19 & $<0.001$ & 4.12 & 2.45 & 0.09 \\
\hline \multicolumn{16}{|l|}{ no } \\
\hline \multicolumn{16}{|l|}{ PCOS } \\
\hline yes & \begin{tabular}{|l|}
-8.87 \\
\end{tabular} & 3.89 & 0.023 & 1.74 & 3.54 & 0.49 & 1.58 & 2.16 & 0.46 & -4.38 & 2.14 & 0.041 & -8.46 & 2.36 & $<0.001$ \\
\hline \multicolumn{16}{|l|}{ no } \\
\hline \multicolumn{16}{|c|}{ Eating disorder } \\
\hline yes & -17.5 & 5.52 & 0.002 & -13.5 & 5.0 & 0.007 & \begin{tabular}{|l|}
-13.1 \\
\end{tabular} & 3.04 & $<0.001$ & -20.1 & 2.97 & 0.001 & 1.41 & 3.38 & 0.68 \\
\hline no & & & & & & & & & & & & & & & \\
\hline
\end{tabular}

The results of regression analyses indicate that age, premenstrual symptoms, and eating disorder were independently and significantly associated with perceived stress. Age had a negative association with perceived stress compared to their peers $(B=-1.45, \mathrm{p}=0.003)$. Moreover, students who were experiencing pain, psychological or mixed symptoms showed significant association when compared to the reference group (acne, bloating, and others) (p-value of 0.003, $0.008,0.002$ respectively). Students with eating disorders had a stronger association with levels of stress $(\mathrm{p}<0.001)$.

In addition, age was independently and significantly associated with physical, social functioning, mental health, and health perception aspects of quality of life. Older students showed significantly higher scores in comparison to their peers ( $\mathrm{p}<0.001,0.001,0.047,<0.001,<0.001$, $<0.001)$. 
The variables that were independently and significantly associated with pain were blood loss, PCOS, and premenstrual symptoms (pain and mixed symptoms).

Eating disorder was a strong independent and significant factor for mental health where females with eating disorder reporting lower mental health compared to those with no eating disorder (beta $=-12.2, \mathrm{p}<0.001$ ).

premenstrual symptoms, blood loos, OCP, and PCOS were independently and significantly associated with Physical functioning.

Those who used OCP or were diagnosed with PCOS also had negative correlation with physical and social functioning. They also reported more pain and had worse health perception.

In addition, those who had to change less than twice or between 5-7 times per day had a positive physical and social functioning and negative association with pain.

Compared to those who had their cycle every 35 days, those who had their cycle less than 21 days or between 21-35 days reported worse social functioning.

Table 6. Multiple linear regression analysis for independent variables associated with quality of life and perceived stress.

\begin{tabular}{|c|c|c|c|c|}
\hline Dependent variable & Independent variables & $\begin{array}{l}\text { Unstandardized } \\
\text { coefficient (B) }\end{array}$ & $\mathbf{t}$ & P-value \\
\hline \multirow[t]{7}{*}{ PSS } & Age & -1.45 & -3.02 & 0.003 \\
\hline & PreSx & & & \\
\hline & Pain & 1.62 & 1.35 & 0.003 \\
\hline & Psychological & 3.48 & 2.67 & 0.008 \\
\hline & Mixed & 3.71 & 3.09 & 0.002 \\
\hline & Acne, bloating, other ${ }^{(a)}$ & & & \\
\hline & Eating disorder (yes) & 4.71 & 4.67 & $<0.001$ \\
\hline \multirow[t]{12}{*}{$\mathrm{PF}$} & Age, years & -3.58 & & 0.007 \\
\hline & PreSx & & & \\
\hline & Pain & -18.41 & -2.87 & 0.004 \\
\hline & Psychological & -14.71 & -2.12 & 0.035 \\
\hline & Mixed & -21.44 & -3.37 & 0.001 \\
\hline & Acne, bloating, other ${ }^{(a)}$ & & & \\
\hline & Blood loss & & & \\
\hline & $<2$ & 17.96 & 2.43 & 0.015 \\
\hline & $5-7$ & 15.56 & 2.06 & 0.040 \\
\hline & $>7^{(\mathrm{a})}$ & & & \\
\hline & Ocp (yes) & -19.01 & -4.79 & $<0.001$ \\
\hline & PCOS (yes) & -8.49 & -2.19 & 0.029 \\
\hline \multirow[t]{5}{*}{ Social function } & Age, yeasr & 1.05 & 1.98 & 0.047 \\
\hline & Cycle length & & & \\
\hline & $<21$ & -15.62 & -2.61 & 0.009 \\
\hline & $21-27$ & -9.89 & -1.96 & 0.050 \\
\hline & $28-35$ & -5.61 & -1.10 & 0.271 \\
\hline
\end{tabular}




\begin{tabular}{|c|c|c|c|c|}
\hline & $>35$ & & & \\
\hline & Blood loss & & & \\
\hline & $<5$ & 25.78 & 3.84 & $<0.001$ \\
\hline & $5-7$ & 21.59 & 3.15 & 0.002 \\
\hline & $>7$ & & & \\
\hline & PreSx & & & \\
\hline & Pain & -14.63 & -2.51 & 0.012 \\
\hline & Psychological & -13.0 & -2.06 & 0.040 \\
\hline & Mixed & -18.77 & -3.25 & 0.001 \\
\hline & Acne, bloating, other ${ }^{(\mathrm{a})}$ & & & \\
\hline & Ocp(yes) & -18.4 & -5.14 & $<0.001$ \\
\hline Mental health & Age, years & 1.33 & 4.15 & $<0.001$ \\
\hline & PreSx & & & \\
\hline & Pain & -3.87 & $\begin{array}{l}-1.09 \\
\end{array}$ & 0.276 \\
\hline & Psychological & -11.94 & -3.10 & 0.002 \\
\hline & Mixed & -10.91 & -3.09 & 0.002 \\
\hline & Acne, bloating, other ${ }^{(a)}$ & & & \\
\hline & Eating disorder (yes) & -12.21 & -4.13 & $<0.001$ \\
\hline Health perception & Age, years & 1.30 & 4.11 & $<0.001$ \\
\hline & Cycle length & & & \\
\hline & $<21$ & 0.992 & 0.273 & 0.785 \\
\hline & $21-27$ & 5.09 & 1.65 & 0.100 \\
\hline & $28-35$ & 7.15 & 2.307 & 0.021 \\
\hline & $>35$ & & & \\
\hline & Ocp(yes) & -4.98 & -2.30 & 0.022 \\
\hline Pain & Blood loss & & & \\
\hline & $<5$ & -12.36 & -2.73 & 0.007 \\
\hline & $5-7$ & -7.26 & -1.56 & 0.119 \\
\hline & $>7$ & & & \\
\hline & PCOS(yes) & -7.47 & -3.23 & 0.001 \\
\hline & PreSx & & & \\
\hline & Pain & 11.37 & 2.88 & 0.004 \\
\hline & Psychological & 3.01 & 0.703 & 0.483 \\
\hline & Mixed & 11.94 & 3.05 & 0.001 \\
\hline & Acne, bloating, other ${ }^{(a)}$ & & & \\
\hline & & & & \\
\hline
\end{tabular}

\section{Discussion}

Menstrual abnormalities have the potential to impact women's health, their physical and emotional wellbeing as well as social and school functioning. There are many ways to assess menstrual abnormalities including cycle length, duration of flow, and amount of blood loss. this study found that $84.7 \%$ of respondents had a normal length cycle, $82 \%$ had normal duration of flow, but only $29 \%$ had normal blood loss, $9.6 \%$ had a shorter cycle ; occurring less than 21 
days , while only $5.7 \%$ had a longer cycle ; every 35 days. These variations in cycle length and duration are consistent with other finding from Rafique and Alshiekh, where they found 13\% of their participants had a short cycle with only $5 \%$ reporting long menstrual periods. ${ }^{1}$ However, other studies done in India and Nigeria, comparable numbers were presented. For example, a study in India found 2.2\% had shorter cycles and 4.1\% had cycles lasting >35 days. 7\% and 24\% occurrence of the same was reported in Nigeria. ${ }^{16,17}$ The current study found that only $29 \%$ had normal blood loss, with most student $67.8 \%$ having hypomenorrhea. These finding might be affected by the respondents understanding of the question, personal hygiene practice, and a true menstrual problem. Only $3.2 \%$ had menorrhagia which is similar to other studies reflecting the low levels of menorrhagia among the younger individuals. Although stress was hypothesized to affect the menstrual cycle, by causing prolonged activation of the hypothalamic-pituitary adrenal axis which may in turn affect the hormonal production leading to abnormal ovulation and menstruation, we found no correlation between menstrual cycle length and duration and levels of perceived stress. These finding are in line with those identified by other authors who studied medical students. However, Zhou et al and Fenster et al, found an association between psychological stress and menorrhagia or polymenorrhea. ${ }^{18,19}$ Allsworth et al, also demonstrated a strong influence from stress as a cause of amenorrhea and menstrual irregularities. ${ }^{20}$ However, these authors studied women from different sections of the community like incarcerated women or those in the military, and while medical students and those studying health sciences in general experience similar amount of stress, due lifestyle, constant performance pressure, and lack of sleep, studies that focused on this group, showed no evidence of any correlation between stress and menstrual abnormalities. Many of our respondents reported some type of premenstrual symptoms with mixed symptoms being the most prevalent $44 \%$, followed by $23 \%$ reporting lower abdominal pain, and $13.8 \%$ had predominant psychological symptoms A strong positive association was noted between those reporting having mixed premenstrual symptoms and levels of perceived stress $(\mathrm{p}<0.001)$. This is supported by findings reported by Rafique et al, where students with a PSS of $>27$ showed a strong positive correlation with premenstrual symptoms $(\mathrm{p}<0.0001) .1$ Similar results were also reported by Kollipaka et al and Gollenberg et al. ${ }^{21,22}$ Another notable finding was that students aged 20 years old or younger were found to have a higher level of perceived stress compared to their peers. This might be explained by the high levels of stress theses students have to experience during the first years to get into the most competitive specialties. Interestingly, when perceived stress was included as a covariant in mulivaraint analysis of quality of life, students aged 20 years or younger were found and compared to their peers were noted to have a negative association with perceived stress $(\mathrm{t}=-3.02$, $\mathrm{p}=0.003$ ). One explanation is that perceived stress was not significantly associated with any of the quality life domains. Another noteworthy observation of the current study is that those who had heavy menstrual bleeding also had significantly high levels of perceived stress. This is in agreement with Vannuccini et al and karlsson et at who showed that women who had heavy menstrual bleeding had high perceived stress and poorer mental quality of life. ${ }^{23,24}$ However, in contrast, Nagma et at found no correlation between menorrhagia and levels of perceived stress among medical students. ${ }^{25}$ These discrepancies in the literature can indicate different methodologies and study populations. Moreover, eating disorders were highly associated with higher levels of stress $(\mathrm{p}<0.001)$. This is most likely related due to other problems that involve having an eating disorder such as distorted body image and poor mental health . Regarding the SF-20 quality of life components, we found that those who had premenstrual symptoms including pain, psychological symptoms, and mixed symptoms did poorly on the physical, 
social, and mental health aspects of quality of life. This in keeping with finding from Hautamäki et al and Bazarganipou et al who have also demonstrated an association between menstrual problems and quality of life and activities of daily living. ${ }^{11,26}$ Furthermore, those with menorrhagia had worse physical, social functioning, and pain. This can be explained by the strong association between heavy menstrual bleeding with level of stress and worse mental quality of life. PCOS with its menstrual irregularities and physical characteristics has been associated with negative body image and self-esteem which contribute to worse overall psychological wellbeing. Surprisingly, we found no significant correlation between PCOS and mental health aspect of quality of life. This contrasts with Bazarganipour et al where they found that PCOS affects women more psychologically than physically. ${ }^{11}$ The current paper, however, did find that those who were diagnosed with PCOS or used OCP, main treatment for PCOS, also had negative correlation with physical, and social functioning more pain and had worse health perception. This suggests that although mental health domain of quality of life was not significantly affected in students with PCOS, they still scored worse on quality of life compared to their peers. Measures taken to improve QOL will inadvertently also treat many psychopathologic issues experienced by student with PCOS.

Study limitations: The current study was strong in many aspects as it included a high magnitude of health science students from different specialties, used validated questionnaires to assess stress and quality of life, and included factors that have not been previously studied such as oral contraceptive pills use. However, it was not without limitations. First, convenience sampling technique was used to collect the data and no statistical calculation of sample size calculation was done. Furthermore, the data relied on information gathered from self-administered questionnaire only, and no history was taken, or medical examination/investigations performed. Second, given cross-sectional nature of the study, the sequence of events between the predictive factors could not be established properly. Moreover, because cross-sectional studies measure exposure and disease at a point in time, findings can be deceptive when attempting to assess relationship directionality and no conclusions can be drawn in terms of causality or any underlying mechanisms. Third, A "healthy volunteer bias" might have occurred due to the inherent nature of the self-selected participants, which may potentially undermine the strength of associations we observed.

Our study has made important conclusions that elucidated the relationship between premenstrual abnormalities, perceived stress, and quality of life. We found that those who had menorrhagia, premenstrual symptoms, or eating disorders reported high levels of stress. We have also demonstrated a link between premenstrual symptoms, menstrual abnormalities, PCOS , and worse quality of life.

We recommend that future studies be conducted prospectively and include a representative sample as to address the shortcoming in the literature. We also recommend that colleges especially those teaching health sciences take those measures to address female students' menstrual abnormalities and stress levels. Improving these factors can help greatly in improving quality of life and in turn overall satisfaction and performance.

\section{References}


1. Rafique N, Al-Sheikh M. Prevalence of menstrual problems and their association with psychological stress in young female students studying health sciences. Saudi Medical Journal. 2018;39(1):67-73.

2. Deliwala KJ, Shah HH, Shah BS. Evaluation of menstrual problems among urban females of Ahmedabad. Journal of Clinical Research Letters 2013; 4: 49-53.

3. Direkvand-Moghadam A, Sayehmiri K, Delpisheh A, Kaikhavandi S. Epidemiology of Premenstrual Syndrome (PMS)-A systematic review and meta-analysis study. J Clin Diagn Res 2014; 8: 106-109

4. Karout N, Hawai SM, Altuwaijri S. Prevalence and pattern of menstrual disorders among Lebanese nursing students. East Mediterr Health J 2012; 18: 346-352

5. Nisar N, Zehra N, Haider G, Munir AA, Sohoo NA. Frequency, intensity and impact of premenstrual syndrome in medical students. J Coll Physicians Surg Pak 2008; 18: 481-484 6. Issa BA, Yussuf AD, Olatinwo AW, Ighodalo M. Premenstrual dysphoric disorder among medical students of a Nigerian university. Ann Afr Med 2010; 9: 118-122.

7. Saipanish R. Stress among medical students in a Thai medical school. Med Teach 2003; 25: 502-506.

8. Liu Y, Gold EB, Lasley BL, Johnson WO. Factors affecting menstrual cycle characteristics. American Journal of Epidemiology 2004; 160: 131-140.

9. Lambert-Messerlian $\mathrm{G}$ et al. First assessment of menstrual cycle function and reproductive endocrine status in Sa- moan women. Human Reproduction (Oxford, England), 2011, 26:25182524.

10. Tay C, Teede H, Hill B, Loxton D, Joham A. Increased prevalence of eating disorders, low self-esteem, and psychological distress in women with polycystic ovary syndrome: a communitybased cohort study. Fertility and Sterility. 2019;112(2):353-361.

11. Bazarganipour F, Ziaei S, Montazeri A, Foroozanfard F, Kazemnejad A, Faghihzadeh S. Predictive factors of health-related quality of life in patients with polycystic ovary syndrome: a structural equation modeling approach. Fertility and Sterility. 2013;100(5):1389-1396.e3. 12. Knox B, Azurah A, Grover S. Quality of life and menstruation in adolescents. Current Opinion in Obstetrics and Gynecology. 2015;27(5):309-314.

13. Nur Azurah A, Sanci L, Moore E, Grover S. The Quality of Life of Adolescents with Menstrual Problems. Journal of Pediatric and Adolescent Gynecology. 2013;26(2):102-108. 14. Ware JE, Sherbourne CD, Davies AR. Developing and testing the MOS 20-item Short-Form health survey: a general population application. In: Stewart AL, Ware JE, eds. Measuring Functioning and Well-Being: The Medical Outcomes Study approach. Durham, NC: Duke University Press, 1992 (in press).

15. Cohen S, Kamarck T, Mermelstein R. A global measure of perceived stress. J Health Soc Behav 1983; 24: 385-396.

16. Omidvar S, Begum K. Menstrual pattern among unmarried women from south India. J Nat Sci Biol Med 2011; 2: 174-179.

17. Fakeye O, Adegoke A. The characteristics of the menstrual cycle in Nigerian schoolgirls and the implications for school health programmes. Afr J Med Med Sci 1994; 23: 13-17.

18. Zhou M, Wege N, Gu H, Shang L, Li J, Siegrist J. Work and family stress is associated with menstrual disorders but not with fibrocystic changes: cross-sectional findings in Chinese working women. J Occup Health 2010; 52: 361-366. 
19. Fenster L, Waller K, Chen J, Hubbard AE, Windham GC, Elkin E, Swan S. Psychological stress in the workplace and menstrual function. American Journal of Epidemiology 1999; 149: 127-134.

20. Allsworth J, Clarke J, Peipert J, Hebert M, Cooper A, Boardman L. The Influence of Stress on the Menstrual Cycle among Newly Incarcerated Women. Women's Health Issues. 2007;17(4):202-209.

21. Kollipaka R, Arounassalame B, Lakshminarayanan S. Does psychosocial stress influence menstrual abnormalities in medical students? J Obstet Gynaecol 2013; 33: 489-493.

22.Gollenberg AL, Hediger ML, Mumford SL, Whitcomb BW, Hovey KM, Wactawski-Wende J, et al. Perceived stress and severity of perimenstrual symptoms: the BioCycle Study. J Womens Health (Larchmt) 2010; 19: 959-967.

23.Vannuccini S, Fondelli F, Clemenza S, Galanti G, Petraglia F. Dysmenorrhea and Heavy Menstrual Bleeding in Elite Female Athletes: Quality of Life and Perceived Stress. Reproductive Sciences. 2020;27(3):888-894.

24.Karlsson T, Marions L, Edlund M. Heavy menstrual bleeding significantly affects quality of life. Acta Obstetricia et Gynecologica Scandinavica. 2013;93(1):52-57

25. Nagma S. To Evaluate the Effect of Perceived Stress on Menstrual Function. journal of clinical and diagnostic research. 2015.;

26. Hautamäki H, Haapalahti P, Savolainen-Peltonen H, Tuomikoski P, Ylikorkala O, Mikkola T. Premenstrual symptoms in fertile age are associated with impaired quality of life, but not hot flashes, in recently postmenopausal women. Menopause. 2014;21(12):1287-1291.

a Bergmann R, Ludbrook J, Spooren WP. Different outcomes of the Wilcoxon-Mann-Whitney test from different statistical packages. Am Statistician 54: 72-77, 2000.

$\underline{\text { ISI | Google Scholar }}$

\section{Declarations:}

- Ethics approval and consent to participate: Approval was obtained from the the institutional review board at King Abdullah International Medical Research Center (KAIMRC). Protocol number: RC20/045/R. Ethical principles stated in the declaration of Helsinki were followed

- Consent for publication: Participants consented to publishing their information

- Availability of data and materials: The datasets used and/or analysed during the current study are available from the corresponding author on reasonable request. 
- Competing interests: The authors declare no competing interests

- Funding: no funding was required for this study

- Authors' contributions: B.A., S.A., M.A., and H.A. have contributed to data collection and manuscript writing and review. In addition, All authors have read and approved the manuscript. All author contributed to data collection and manuscript writing and editing

- Acknowledgements: The authors would like to acknowledge Dr. Alaa Althubaiti, Biostatistician, King Saud bin Abdulaziz University for Health Sciences, without whom this work would not have been possible 

